\title{
Transport geography, climate change and space: opportunity for new thinking
}

\author{
Tim Schwanen \\ Transport Studies Unit \\ School of Geography and the Environment \\ University of Oxford \\ E-mail: tim.schwanen@ ouce.ox.ac.uk
}

Accepted for publication in Journal of Transport Geography on 6 September 2019

Published as:

Schwanen, T., 2019. Transport geography, climate change and space: opportunity for new thinking. Journal of Transport Geography 81: 102530. 


\title{
Transport geography, climate change and space: opportunity for new thinking
}

\begin{abstract}
This paper reflects on how Transport Geography has examined the relationships between climate change, transport and space. It identifies four tendencies in engagements so far - uneven attention; separation between climate change mitigation and adaptation; continuity in theory, method and research praxis; and over-reliance on 'Western' thinking and worldviews. It develops an agenda for further research that emphasises the importance of considering all modes and forms of transport, moving beyond the mitigation and adaptation distinction, and the socio-political nature of the relationships between climate change, transport and space. It also argues that research praxis has to be revised if those relationships are to be understood adequately, suggesting that critical reflexivity on concepts is a useful step in this direction. The paper then introduces and illustrates an approach to the (re)invention of concepts about the relationships between transport, climate change and space. It concludes by urging transport geographers to work with concepts co-produced with a much wider range of constituencies than usually considered and to develop new methods for tracking the events created by new concepts.
\end{abstract}

Keywords: transport geography, climate change, concept, adaptation 


\section{Introduction}

The links between anthropogenic climate change and transport hardly require introduction. It is well known that transport, as the prime source of oil demand, accounts for approximately a quarter of global $\mathrm{CO}_{2}$ emissions (IPCC, 2018). It is equally evident that transport configurations - the ensembles of infrastructures, technologies, practices, regulation, meanings, values, affects enabling and shaping the (non)movements through physical space of people, goods and waste - are often extremely vulnerable to disruption by weather events that are likely linked to changing climatic conditions, from heat stress to storm surge and 'super storms', and that both vulnerabilities and their effects are spatially and socially uneven (IPCC, 2014). Transport Geography has recognised the relationships between climate change, transport and space for quite some time, and some of the best-cited papers in Journal of Transport Geography discuss them directly (Chapman, 2008; Geels, 2012).

Nonetheless, in this paper I argue for change in how Transport Geography engages with questions related to climate change. This is not in any way meant to invalidate or debunk how the relationships between climate change, transport and space have been dealt with in Transport Geography scholarship so far. Yet, I do believe climate change is triggering, and should trigger, a problematisation of how transport geographers approach, conceptualise and examine those relationships. In this context, 'problematisation' is a practical response in which "provoked by a concatenation of events ... 'domains of action' become objects for reflection" (Barnett and Bridge, 2016, page 1192; see also Rabinow, 1997). It thus highlights 
that the emergent and (place) specific qualities of climate change are intensifying the uncertainties, difficulties and challenges that transport geographers are negotiating as part of the practice of undertaking their research.

Those qualities relate first and foremost to the planetary character of climate change, meaning that events in one time and place are linked in complex ways to current, past and future events elsewhere in the world. They also relate to the profound uncertainties over the speed with, and time horizons over, which changes are and will be occurring and what the effects will be; what will happen, when, where, for whom/what, in or to what transport configuration is unknown. This is not least because, for thinkers such as Isabelle Stengers and Bruno Latour, the "margin of tolerance [of the planet and its atmosphere] has been well and truly exceeded" (Stengers, 2015, page 45) after centuries of industrialisation, development and relentless quests for growth and wealth. A 'new climatic regime' (Latour, 2018) has emerged in which the previously relatively stable relationships between planet, atmosphere and civilisation are drastically reconfigured in ways that remain largely unclear. To an extent the absence of clarity is a form of epistemic uncertainty, a 'not-yet-knowing' that will diminish over time when events unfold and more information on patterns of change becomes available. Yet the uncertainty is also ontic. The non-human world may always have been more "event-full" and active than mainstream Euro-American knowledge has appreciated (Latour, 1993, 2018), but its capacities to intrude upon transport configurations are now so variable and forceful that the limits on their knowability 
to humans, including scientists, must finally be respected (cf. Morton, 2013; Stengers, 2015). ${ }^{1}$

The second part of my argument is that one possibility to push Transport Geography research on the relationships between climate change, transport and space into new directions and territories is the elaboration of new and renewed concepts. This is only one way among many, but a focus on concepts can open up new understandings, imaginations, experiences and modes of action with regard to the future of transport configurations. These propositions are informed by the thinking of Gilles Deleuze with and without Félix Guattari about concepts. From their writings on concepts as creative responses to problems a number of insights can be derived that are directly relevant to Transport Geography's engagement with questions of climate change, transport and space. Some of these insights will be illustrated in a brief discussion of the concept of adaptation. However, I also believe that we need to move beyond Deleuzian thinking on concepts as their creation cannot be left to philosophers or specialists in established centres of academic knowledge production, most of which are located in the global North; a diversification of who (re)invents concepts regarding the relationships between climate change, transport and space is desirable. Before being able to elaborate that claim, I first have to reflect on how Transport Geography has addressed climate change so far.

\footnotetext{
${ }^{1}$ The increased interconnectivity and complexity of transport configurations, both in specific places and globally, only intensifies the limits on the extent to which capacities for intrusion can be known.
} 


\section{Climate change in Transport Geography}

Providing an overview of all the ways in which transport geographers across the planet are engaging with anthropogenic climate change is beyond this paper. The discussion will instead be limited to four general observations.

\subsection{Unevenness and separation}

A first observation is that attention to climate change remains unevenly distributed across the various sub-fields and research traditions within the broad church of Transport Geography. As demonstrated elsewhere (Schwanen, 2016a), climate change is most prominently addressed as a concern in geographical research on urban passenger mobility, and a review of recent publications in Journal of Transport Geography confirms this (see e.g. Chow, 2016; Zhao et al., 2017; Keskisaaria et al., 2017; Conti, 2018). There continues to be only limited interest in climate change in Transport Geography work on freight, on aviation and maritime transport. There are, of course, exceptions to this claim, as exemplified by Luo et al.'s (2017) analysis of regional disparities in $\mathrm{CO}_{2}$ emissions from freight transport in China and studies of such emissions in aviation (Caset et al., 2018; Markham et al., 2018) and container ports (Na et al., 2017). Nonetheless, not all parts of Transport Geography devote due attention to climate change.

Secondly, the Transport Geography community tends to accept the separation between climate change mitigation and adaptation that since the mid-1990s (IPCC, 1995) has gradually become institutionalised within the Intergovernmental 
Panel on Climate Change (IPCC, 2001 and subsequent reports) and in national policy in many countries. Not only does research on the relationships between climate change, transport and space have a tendency focus on one or the other; mitigation also continues to be favoured over adaptation. However, the imbalance does not seem to be as strong as it was at the start of the decade (cf. Schwanen et al. 2011). Particularly in recent years has there been a rapid expansion of the literature on disruption to transport services and travel patterns due to weather events (e.g. Dawson et al., 2016; Brazil et al., 2017; Corcoran and Tei, 2017; Ferranti et al., 2017). There is also growing interest in what sea level change means for ports and maritime transport (e.g. Ng et al., 2013; Becker et al., 2018), recently complemented by work focused on the opportunities that the changing temperatures in the Arctic are opening up for maritime transport (e.g. Huang et al., 2015; Lasserre et al., 2016; Ng et al., 2018).

Given transport's large and growing contribution to global $\mathrm{CO}_{2}$ emissions (IPCC, 2018), the privileging of climate change mitigation in Transport Geography scholarship is understandable. Nonetheless, more attention needs to be directed towards climate change adaptation for at least two reasons. Extreme weather events that are likely to be linked to climatic events are already having major implications for transport configurations across the globe, and often in socially and spatially unjust ways. The transport-related effects of Hurricane Katrina are perhaps best documented (Cresswell, 2006; Litman, 2006; Sanchez and Brenman, 2008). Nonetheless, ongoing research in the Philippines in which I am involved (Plyushteva and Schwanen, 2018) offers insight into how typhoons and much less extreme weather events disrupt transport configurations with short- and long-term, 
spatially and socially uneven effects for residents (e.g. disruption to daily activities and income generation, or postponement of vehicle purchases).

In addition, most research on climate change adaptation in transport has a technocentric and engineering-oriented focus. It goes without saying that changes to physical infrastructures like roads, railway tracks and ports to make them more robust against high temperatures, irregular and intensive precipitation and sea level rise are critically important. Also, engineering-oriented research that helps normalise climate change adaptation, embedding it into 'business as usual' infrastructure planning and management (e.g. Quinn et al., 2018), is indispensable. Yet, this is not sufficient and only part of what is required, because climate change adaptation in transport - as in other domains - is both postpolitical $^{2}$ (Swyngedouw, 2009) and power-laden and shaped by vested interests, as well as often socially and spatially uneven (see also Lucas and Pangbourne, 2012). There exists, then, an urgent need for research on transport, climate change adaptation and space by geographers who work from political ecology, morethan-human geography and other approaches that flourish across Geography.

\subsection{Continuity and coloniality}

The third observation is that there are strong continuities in terms of theory, method and research praxis when it comes to how transport geographers address the relationships between climate change, transport and space. Insofar as climate

\footnotetext{
${ }^{2}$ A situation in which radical dissent has been erased from thought and practice regarding a particular issue or problem and in which addressing that issue or problem is reduced to consensus formation, technocratic management and problem-focused governance.
} 
change is fundamentally different from other 'challenges' - air pollution, physical inactivity, road congestion, social exclusion, economic decline or disadvantage of particular territories, and so forth -, it is usually not understood to demand its own and specific theories, concepts, logics, methods and research practices. I most emphatically do not suggest that transport geographers are engaging questions of climate change, transport and space in unthinking or mechanistic ways. Yet, their engagement might still be characterised as habitual - here understood not in terms of mechanical repetition that stands in direct opposition to reflexive thought but, after Dewey (1922), as “embodied, acquired, thought-imbued sensitivity to the negotiation of practical situations" (Barnett and Bridge, 2016, page 1197). ${ }^{3}$

While thought is evidently part and parcel of transport geographers' largely habitual ways of dealing with the relationships between climate change, transport and space, it has so far kept research in the orbit of what has gone before. This has had multiple effects. One is that, as far as $\mathrm{CO}_{2}$ emissions reduction in transport is concerned, there is broad agreement in Transport Geography - and Transport Studies more generally - that goals are to be achieved through a combination of technological change, the provision of low-carbon infrastructures and services, behaviour change, better integration of transport with urban and land use planning, and streamlining of institutions for governance and delivery (see also Schwanen et al., 2011). These are also the interventions on which research tends to concentrate, often privileging one type over the others and without offering indepth analysis of interactions and interconnections (e.g. considering only what

\footnotetext{
${ }^{3}$ The distinctive genius of Dewey's (1922) notion of habit is that it does not exclude thought in the form of reflexivity in response to the situation one finds oneself in. Habit is therefore best thought of as a history-dependent, more-than-individual orientation towards action in the world.
} 
contribution rapid diffusion of electric vehicles (EVs) can make to transport's decarbonisation).

In addition, transport geographers often address the relationships between climate change, transport and space by integrating them with other 'challenges' under the umbrella of sustainable transport. The appropriateness of this strategy can nonetheless be questioned. Climate change is neither simply bio- or geophysical in nature nor independent from other problems. This is why decolonial theorist Sylvia Wynter refers to "a poverty-hunger-habitat-energy-trade-populationatmosphere-waste-resource problem, none of whose separate parts can be solved on their own" (Wynter and McKittrick, 2015, page 44). Latour (2018) also draws attention to the interconnections of the bio- and geophysical aspects of climate change with deregulation, socio-spatial inequality, international migration and climate change scepticism and denial by certain politico-economically powerful groups. Still, there are clear differences between climate change and the problems to which it is linked, implying that climate change demands a specific response from transport geographers (and other researchers). After all, climate change has unique long-term, intergenerational and planetary dimensions for which the latest evidence suggests that time to mitigate the worst effects is running out rapidly (IPCC, 2018) whilst it is highly questionable that, despite 2018's Paris Agreement, the required governmental capacities and political will are really in place. Besides, climate change is foreseen to have - and already seems to be having - specific capacities to disrupt transport configurations in different parts of the world and operating at different geographical scales. 
Moreover, the largely habitual ways of dealing with the relationships of climate change, transport and space have also helped to reproduce in some quarters of Transport Geography a keen interest in logics of speeding up and increasing efficiency that have since mid- $20^{\text {th }}$ century been at the heart of technical-rational transport planning. These logics are no longer applied as enthusiastically to road construction and expansion as they were in the $20^{\text {th }}$ century, at least in the global North. ${ }^{4}$ The emphasis has now shifted to high-speed rail, bus rapid transit, and smart mobility, and at least some transport geographers have been cautiously optimistic about their contribution to reduced $\mathrm{CO}_{2}$ emissions from transport (e.g. Givoni and Banister, 2013; Loo, 2018). However, in the past the logics of acceleration and efficiency have not always delivered the promised level of reduction in transport activity and energy consumption, with some of the anticipated reductions cancelled out by complexities in human behaviour and decision-making. This, at least, is one way to synthesise some of the (not uncontested) headline findings of research on stable travel time budgets (Zahavi and Talvittie, 1980; Hupkes, 1982; Mokhtarian and Chen, 2004), induced demand of increased infrastructure capacity and accessibility (Noland and Lem, 2002; Thill and Kim, 2005; Givoni, 2006), and direct rebound effects of energy efficiency improvements in transport (Stapleton et al., 2015; Sorrell and Stapleton, 2018). Depending on the situations they find themselves in, individuals, households and firms may not minimise their travel or energy consumption but rather travel or consume more. This implies that, at a minimum, the logics of acceleration and efficiency increase - and the assumptions of human action they

\footnotetext{
${ }^{4}$ However, road construction and expansion is an important part of the repertoire of interventions the UK government has put in place to regenerate the economy after the protracted downturn after the 2008 Financial Crisis.
} 
entail - need to be refined, complicated and accompanied with numerous caveats when applied to low-carbon transport. An alternative is to move away from them altogether. This is not unreasonable given that these logics were, in the mid- $20^{\text {th }}$ century, developed and adapted to facilitate and legitimise the expansion of oildependent transport configurations (see also Bonham, 2006; Boyce and Williams, 2015; Weiner, 2016). One may therefore wonder whether they constitute the best basis for the radical reconfigurations - including absolute declines in motorised transport volumes - that are now required.

Finally, Transport Geography research on the relationships between climate change, transport and space remains firmly ensconced in Euro-American ontology, epistemology and methodology. The argument developed elsewhere (Schwanen, 2018) that expert knowledge about transport more generally remains under the influence of - and through its uptake in planning, education and research helps to reproduce - coloniality is equally valid for the ways in which transport geographers address issues of climate change. The concept of coloniality was originally proposed by Anibal Quijano and later developed by other decolonial theorists. It refers to the legacies of Western-European colonialism in Latin America and the Caribbean, as well as Africa and Asia, and to the continued relevance of social, political and economic hierarchical orderings imposed during Western-European colonisation after gaining statehood (Quijano, 2000). As Mignolo (2011) explains, these orderings operate in the interrelated domains of the economy, authority, gender and sexuality, and knowledge and subjectivity. They manifest themselves in numerous ways, of which two merit mention here. One is the tendency to posit Western Europe as the model and the destination to 
which other parts of the world will progress, or should at least aspire to progress. This tendency manifests itself in myriad ways in relation to transport, with one of the most recent being the normalisation of cities like Amsterdam or Copenhagen as exemplars for cities across the world - irrespective of climate, culture, history and urban form - about how to promote cycling. The other is the tendency in research to see sites across the global South as merely generating data that are to be interpreted using theories that have developed in the North and/or by Northern academics (McCann et al., 2013).

New concepts and theories that have been taken up in Transport Geography research about the relationships between climate change, transport and space also remain firmly rooted in 'Western' thinking and research traditions. This is, for instance, the case with the powerful thinking on sociotechnical transitions originally developed in the Netherlands in the 1990s (e.g. Rip and Kemp, 1998; Hoogma et al., 2002; Geels, 2012). This body of knowledge has had significant impact on Transport Geography by animating empirical research (e.g. Schwanen, 2015a; Upham et al., 2015) and by helping to normalise the term 'transition' to denote deep structural change in transport configurations among a wider range of researchers (e.g. Loo, 2018; Marsden and Reardon, 2018). Most recently, Ghosh and Schot (2019) have begun to adapt sociotechnical transitions thinking to changes in urban mobility in non-western contexts. However, neither these authors nor other transition scholars examining transport seem to have directly engaged with Indigenous or local knowledges about global environmental change - the understandings, skills and philosophies of communities and societies in particular localities with long histories of interaction with their natural or material 
surroundings and whose metaphysics and ontologies need not align with mainstream Euro-American knowledge(s). ${ }^{5}$ This stands in contrast to both other parts of the discipline and interdisciplinary research on global environmental change (e.g. Ishaya and Abaya, 2008; Cameron, 2012; McCreary and Milligan, 2014; Owusu et al., 2019). Opening up research on the relationships between transport, climate change and space to the voices and perspectives of a wider range of constituencies, including residents of informal settlements in Southern cities and Indigenous peoples, as genuine co-producers of specialist knowledge is likely to enrich academic Transport Geography immensely. It is nonetheless essential that all of this occurs on their terms and using non-colonising and nonextractive ontological, epistemological and methodological frameworks to avoid extractive and neo-colonial relationships. This will require a significant overhaul of research praxis in Transport Geography.

\subsection{Priorities and needs}

Multiple priorities and wider needs for Transport Geography research on climate change can be derived from the above discussion. For instance, as complement to the focus on urban personal transport, much more research effort needs be directed towards climate change mitigation in maritime, air and freight transport as well as to climate change adaptation in each and every transport configuration. This and other research on the interrelationships of transport, climate change and space would also benefit from moving away from technical-rational approaches to

\footnotetext{
${ }^{5}$ That said, recent literature on the opening up of the Arctic for global maritime transport does recognise the "risks to local autonomy and sovereignty" of "peoples whose traditional livelihoods depend on [wildlife] resources" (Ng et al., 2018, page 14).
} 
climate change mitigation and adaptation that are preoccupied with logics of efficiency and speed. Research might rather consider how, in particular settings, places and spatial configurations, a series of issues and processes play out around:

a) Discourse, problematisation, responsibility and capability: How are issues around transport and climate change constituted discursively? What is rendered a problem, what a solution? Who/what is assigned and/or takes up responsibility to act? To what extent and in what way is action made possible?

b) Justice in terms of distribution - who/what gains or looses where, when and how?; recognition - to what extent are different actors, communities, knowledges and cultures respected and valued in discourse and practice (e.g. Fraser, 2008)?; and procedure and representation - how are particular outcomes achieved? Who gets to participate and on what terms?

c) Politics and the political: Which concerns, instruments and actions get prioritised in parliaments, boardrooms, planning departments, strategy workshops and the like ('Politics') and everyday life ('politics')? What space is created for genuine dissent and contestation around discourse, problematisation and action (cf. Mouffe, 2005)? What are the responses to such dissent and contestation?

d) Path dependencies: how are all of the above shaped by habits and routines in the thinking and praxis of governments, corporations, citizens and other constituencies in particular places and spatial configurations? How are radically new modes of thought and action nourished and allowed to flourish? 
In addition to expanding the research agenda with regard the relationships between transport, climate change and space, transport geographers should critically consider how they understand and examine those relationships, so that the above issues and processes as well as the specific challenges that climate change poses can be understood adequately. A critical step in this regard is reflection on, and (re)invention of, concepts because these often function as building blocks for theories and inform many of the methods that transport geographers use.

It is, however, not immediately apparent how this can be done in a methodologically robust manner. One possibility is to turn towards philosophy. Evidently, many philosophers' works could be considered but that of Gilles Deleuze - with and without his long-time collaborator Félix Guattari - is a prime candidate in this context. His thinking on concepts is considerably less wellknown and appreciated in (Cultural) Geography and Continental Philosophy than that on, say, assemblages, multiplicity or virtuality but it is original, robust and most importantly - eminently suitable for critical consideration of how the interrelationships of transport, climate change and space are understood. Deleuze's emphasis on disruption of habitual thinking and orientation towards complexity, dynamism and the limits of representation are particularly useful in the context of how Transport Geography addresses issues of climate change.

\section{Towards new concepts}

\subsection{What does a concept do?}


The conventional way of thinking about a concept is as a more or less universal description of an object or a class of object (Cook, 1998). Implied is a model of correspondence of truth in which the variability and complexity of the real world is captured by a concept as a representation that abstracts away many of the (insignificant) specific features, history and other particularities of that (class of) object. Consider, for instance, 'vehicle' - commonly used in transport and mobilities research to denote all kinds of entities that have at least one wheel and can move, or be moved, through physical space. Cars, vans, bikes are lower-order concepts that can be subsumed under the vehicle concept, each representing all kinds of objects that can be encountered in the real world at particular places and times.

Deleuze was not so much interested in the question what a concept is as in what it does - i.e., which effects it generates. He did not deny that concepts have a descriptive function but rather held that their role was, and should be, more complex (May, 2005). Together with Guattari, he argued that concepts are or become expressive, meaning they have or acquire a performative function (Deleuze and Guattari, 1994). The whole point of a concept, for Deleuze, is to "bring about a new way of seeing something and not simply fix a label to something we think we already know" (Buchanan, 2017, page 474). Rather than reproduce what is already familiar, good concepts help to estrange and experiment - to think, feel, imagine and act in new ways and thereby contribute to the constitution of a different world. That is, their creation generates an 'event', a 
rupture - however small - between what went before (a problem, see below) and what come after (new thoughts, feelings, imaginations, actions).

Events occur when a concept disrupts habitual thinking in relation to a specific topic. Consider, for instance, how the aforementioned concept of coloniality slows down the unreflective use of ideas, logics and theories about, say, the relationship between transport and spatial change that have originally been developed in the global North to make sense of empirical observations across the South. Consider also how Hägerstrand's concept of the space-time prism has reconfigured thinking about accessibility in Geography and beyond by drawing attention to time constraints that differ between individuals and social groups and the "principle of return' - the need for people to return to a 'base' location such as their home (Hägerstrand, 1970). The capacity to disrupt habitual thinking is particularly useful given the strong continuities in how transport geographers imagine and examine the relationships between transport, climate change and space and because of the specific and unique nature of climate change as a problem (see Section 2.2 above).

For Deleuze concepts generate events in other ways too. As May (2005) suggests, good concepts palpate, gesturing at what they cannot grasp and what eludes description. On this view, description using words, numbers and visualisations renders the world more stable than it actually is by 'freezing' it or conceiving it as a sequence of individuated and stable elements or states. As a result, description cannot fully capture the complexity and dynamism of the world and hence its 
potential to change and become or be otherwise. Good concepts, in other words, recognise and hint at multiplicity, process, indeterminacy and uncertainty.

Deleuze and Guattari (1994) nonetheless recognise that concepts do not emerge out of thin air. They emphasise that concepts are responses to specific problems (on which they shed a new light and which they help to redefine). There are two implications to this view. First, concepts have no meaning beyond the problem they address and always need to be evaluated in relation to the problem(s) to which they respond (Deleuze and Guattari, 1994, page 16). This not only makes it difficult to compare different concepts directly with each other, but also complicates the criticising of concepts. The latter is only possible when the problem to which a concept responds is considered. On this view, a focus on concepts entails a shift in orientation from the solution of a problem to its definition and specification. This is particularly helpful in relation to thinking about climate change, for it opens up opportunities for moving beyond climate change as either caused by greenhouse gas emissions from transport and other activities or as something from which transport systems in particular places need to be protected. Sylvia Wynter's holistic view on climate change discussed above thus become easier to accommodate. Second, given that problems tend to change over time, concepts have to change continually too. This is why Deleuze thought of concepts as "living things, ... things with four paws, a thing that moves, really. It's like a color, like a sound" (Deleuze, 1998, page 79).

Deleuze and Guattari (1994, page 19) furthermore appreciate that concepts "are never created from nothing." Concepts relate to and build upon past and present concepts developed by others. Deleuze and Guattari also suggested that concepts 
consist of closely interwoven, inseparable components that give them their consistency.

\subsection{Implications for Transport Geography}

Deleuzian thinking about concepts encourages transport geographers in general and especially when directing their attention to the interrelationships of transport, climate change and space to develop concepts that disrupt habitual thinking within academia and beyond, and that gesture at that which defies direct description. This may seem, and in some ways is, a daunting task, but there are precedents from the broader literatures on transport and mobilities in Geography to build upon or learn from. There are, for instance, many examples of how concepts have disrupted habitual thinking. Hägerstrand's (1970) space-time prism has already been discussed; other examples include transport-related social exclusion (Preston and Rajé, 2007; Lucas, 2012), automobility (Sheller and Urry, 2000) and motility (Kaufmann, 2002). Concepts that palpate are scarcer in Transport Geography; one example is offered by my elaboration of the smartphone app as an object on the basis of Graham Harman's object-oriented ontology (see Schwanen, 2015c). This clearly is an area where extensive experimentation is required.

At the same time, transport geographers need to think carefully about not only what problems concepts respond to, but also whose problems, where and whence. If, as Deleuze insisted, problematisations are dynamic and changing, then concepts need to be (re)invented continually. There is, however, also a spatial 
element to this: since problems are situated geographically and play out differently across space (e.g. because they are affected in different ways by coloniality, globalisation or changes in temperature and precipitation), then concepts need to respond to and incorporate not only (global) circulation of current and past thought in academia but also engage and recognise differentiated and particular knowledges and experiences in specific places. The (re)invention of concepts can be decentred to such an extent that local communities of human and non-human agents in particular locales and transport geographers become approximately equal participants in the process, but this is not a necessary condition. More likely is a situation where the latter are inspired and affected by interactions with such communities and undertake the (re)invention. Either way, concepts and conceptualisation should not only be temporally but also spatially situated and specific.

This call for spatial articulation and differentiation of the (re)invention of concepts also raises the question to what extent a Deleuze-inspired approach can be and should be adopted everywhere across the planet. Conversations between post-colonial and Deleuzian scholarship range from being critical (Spivak, 1988) to seeking rapprochement (Bignall and Patton, 2010; Burns and Kaiser, 2012; Dorries and Ruddick, 2018; Medien, 2019). Bignall and Patton (2010, page 3) have claimed that "many of Deleuze's philosophical writings, both alone and with Guattari, develop concepts and frameworks of discussion that resonate with themes and issues pertinent to postcolonialism". They also document Deleuze's active involvement in decolonisation efforts in Algeria and Palestine (see also Medien, 2019). At the same time, his thinking, including that on concept creation, 
remains firmly entrenched in the Western-European philosophical tradition. Even though he was a scathing critic of many of the assumptions underlying coloniality, there are certain incommensurabilities between his work and Indigenous philosophies (see Dorries and Ruddick (2018) for further discussion in relation to one specific Indigenous philosophy). To what extent the ideas of Deleuze (and Guattari) about concept creation are commensurable with such philosophy needs to be considered on a case-by-case basis. Experimentation with other ways of renewing thought on the relationships between climate change, transport and space may also be required.

\subsection{Reworking adaptation: a brief example}

Recall from Section 2.1 the observation that a wedge has been driven between climate change mitigation and climate change adaptation and the former privileged over the latter in Transport Geography research. This wedge was not the intention of the IPCC in the late 1990s. Its Third Assessment Report (IPCC, 2001, page ix) explained that the mitigation and adaptation were discussed in separate reports to offer more detailed discussion of themes such as sustainable development, equity, scientific uncertainty, costing and decision-making frameworks and foregrounded that climate change adaptation was "a necessary strategy at all scales to complement climate change mitigation efforts" (page 6). The interweaving of climate change mitigation and adaptation has faded into the background in many discussions about transport, also - as discussed above - in Transport Geography. 
Whilst at first going along with this distinction, and indeed contributing to it through research, I became increasingly troubled because of situations of which I was part. Decisive in this regard was research in Manila and London about everyday mobilities in low-income, centrally located neighbourhoods and the governance of transport configurations' vulnerability to flooding (e.g. Plyushteva and Schwanen, 2018). This is the problematisation that triggered the experimental attempt at concept creation, which is introduced here as an illustration of the points made in the preceding discussion.

A concept can be a neologism but not necessarily: "sometimes you will take a very common word; it will be ... there the best fit" (Deleuze, 1980, no pagination). In the case discussed here, I opted for adaptation. Although it may seem counterintuitive, adaptation as I propose to understand it can reconnect climate change mitigation and climate change adaptation in transport configurations. This is particularly so if we start from a process-based worldview (as has been advanced by, for instance, Alfred North Whitehead and Isabelle Stengers), in which every seemingly stable object or being is actually constantly reproduced and thus becoming with ever so slight variations, and in constant interaction with its environment (see also Schwanen, 2015b, 2016b). A person, a car, an airport, the worldwide 'complex systems' of maritime transport, and so forth are never identical at different times, not even from one nanosecond to the next. In other words, entities are here constantly changing in ways that cannot fully be known in advance. Adaptation is then a specific kind of change, one that is inherently future oriented and seeks to secure an entity's persistence, given inevitable uncertainty 
about what the future might bring, and without compromising the capacities of other entities to secure their persistence. It thus implies some kind of learning about the consequences of past actions and a disposition of humility and openness towards the future: what will happen cannot be known in advance but preparation for many different happenings and unfoldings is feasible. Such preparation will always be what Stengers (2011) calls divergent. With this, she does not mean differing from what other entities do/become or from a generic standard or norm (which can be identified in empirical research). She rather tries to bring out that each entity seeks to pay due attention to the specific situations that matter to it. This understanding of divergence is important, for it challenges the assumption that generic guidelines and standards - including 'best practice' - regarding how, say, a city or a port can minimise greenhouse gas emissions and prepare itself for storm surge, forceful winds or heat stress are desirable or useful.

Space constraints preclude an elaborate discussion of my version of adaptation, a concept that could, of course, have been developed in other ways. Suffice it to say, firstly, that qua concept adaptation has several, closely linked components: open futures, persistence, preparedness, and justice. The thinking on persistence it embodies goes back to the concept of conatus - the inclination or striving of an entity to continue in its existence and enhance itself - which was particularly popular in $17^{\text {th }}$ century Western-European philosophy (e.g. Spinoza, Leibniz) and repeatedly drawn upon and reworked subsequently (e.g. Ravaisson, Deleuze). The justice component is evident in the emphasis that is placed on entities not robbing other entities of their opportunities to persist. This has significant implications, given that the expansion and smooth operation of automobility and airports 
depends on the immobilisation of certain groups of people - public transport captives and many pedestrians and cyclists in the former case, ground staff and non-elite passengers in the latter (e.g. Cresswell, 2006; Henderson, 2006; Sheller, 2015). Adaptation as it understood here may be difficult to realise in many places implicated in the transport configurations centred on the car and airplane.

Secondly, the adaptation concept begins to shed a different light on both climate change mitigation and climate change adaptation in relation to transport. It responds to the two problems of the wedge between climate change mitigation and climate change adaptation, and the social and spatial inequalities inscribed into and reproduced by both types of action. For not only do they become two sides of the same coin of preparation for the future based on inevitably contextspecific learning from the past; the concept also places (distributional) justice at the heart of them. In fact, on users the concept imposes the obligation to ask who/what benefits from a particular type of action and at the expense of who/what. It thus offers a different perspective on forms of climate change adaptation that make climate change mitigation more difficult, because they either promote or reinforce carbon-intensive transport (e.g. aviation, motorway traffic) directly by increasing the speed or efficiency of movement, or diminish people's capacities to make changes to mobility practices in order to reduce emissions. An example of the latter - observed in Manila - is the creation of better drainage for certain roads or elevating particular roads and thereby increasing the risk of flooding elsewhere in the city (and particularly in lower-income areas). This in turn may adversely affect the health, livelihoods and capacities of enact behaviour change in transport or other domains of everyday life of the people living there. 
The concept of adaptation also throws a different light on forms of climate change mitigation that are decoupled from consideration of changes in weather and climatic conditions. It throws into doubt the blanket promotion of cycling as a universally applicable mitigation strategy, including in locations where the practice can become a genuine risk to human health in future when heat stress, winds or variability in precipitation intensify. ${ }^{6}$ It even draws attention to some of the risks associated with EV charging. Future recurrent changes to weather patterns may destabilise grid performance (especially when wind and hydropower make up large shares of the energy mix in a territory) and expose vehicles and even the persons charging them to extreme temperatures, wind and precipitation. This may appear as exotic to research in global North locations with benign climates but pose real issues for many, especially socioeconomically disadvantaged groups in cities across Africa, Asia, Latin-America and the Caribbean.

Finally, the above discussion demonstrates that the concept of adaptation as elaborated here can and does disrupt habitual thinking. To an extent it may even estrange some audiences, for instance those for whom cycling promotion is inherently and universally desirable. Moreover, the concept also palpates, gesturing at what eludes description. Adaptation in transport configurations, and all the entities that constitutes it, is after all constant, divergent, multiple and

\footnotetext{
${ }^{6}$ Cycling promotion can of course be an important way of reducing emissions from transport but not everywhere, always and for all social groups.
} 
uncertain. It cannot be represented - certainly not by the conceptual categories routinely used in Transport Geography - or known in full.

Being vicariously aware of adaptation's multiplicity and uncertainty is nonetheless useful and important for researchers, among others because it can sensitise them towards marginal forms of change that bear on the linkages between transport and climate change, however modest the effects may be. Consider, as an example, actions by employees in a particular organisation to have showers installed in the office. In itself this is not necessarily related to climate change but it becomes relevant if it supports commuters in switching to cycling. Whilst rarely highlighted in academic studies (but see Spotswood et al., 2015), social expectations and norms around sweat and bodily hygiene make cycling unattractive for many workers, especially those in functions involving extensive face-to-face contact with others. Expanding shower facilities is no panacea but can contribute to reduced emissions from transport, even if this is an intervention that normally remains beyond the purview of transport geographers and scientists. Adaptation's gesturing at ongoing, dispersed and indeterminate change in/around transport configurations does not simply draw attention to (potentially bedazzling and overwhelming) complexity; it can also cultivate among geographers and others an openness to the myriad actions that reconfigure the relationships among transport, climate change and space and the need to continually revise the categorisations used to study those actions.

The discussion in this sub-section offers only one example of how a concept can be (re)invented in response to a specific problem as I have come to understand it. 
Other problems regarding the relationships between transport, climate change and space or the ways in which transport geographers understand them will require other concepts. There are no ready-made answers to the questions which concepts need to be (re)invented and how this should be done. Trial and error as well as a focus on challenging taken-for-granted conventions and on complexity and uncertainty can be useful and may help push transport geographers' engagements with climate change into new directions.

\section{Conclusions and outlook}

This paper has identified two priority areas for research about the relationships between transport, climate change and space - an expansion of the substantive topics that are being addressed and critical consideration to concepts as a response to the ways in which climate change is problematising established research praxis. It has outlined a research agenda that covers all modes and forms of transport, moves beyond the institutionalised segregation of climate change mitigation and climate change adaptation, and resists the reduction of both to technical questions. That agenda foregrounds questions of discourse, capability, justice, the political and path dependency in specific settings, places and spatial configurations. A crucial idea animating the paper is that transport geographers' engagement with climate change cannot remain limited to doing more research. The ways in which they conduct their research also need to change although it is immediately clear how. Starting with a focus on concepts and particularly the (re)invention of concepts may be useful first step. Drawing on the work of Deleuze (and Guattari) 
is effective in this regard because it offers a pathway to the development of more concepts that disrupt habitual modes of thinking and cultivate an openness to complexity, dynamism and uncertainty. The resulting changes to how transport geographers think about the relationships between transport, climate change and space can make realisation of the research agenda above easier. They can also generate insights that help and empower policymakers, NGOs, businesses and citizens in their attempts to reconfigure the relationships between transport and climate change across the planet.

Nonetheless, both the research agenda and the thinking on the (re)invention of concepts, illustrated through a reworking of adaptation, in this article are preliminary and partial. This is not least because this paper is suffused in so many ways by a 'Western' perspective and written from one of the most privileged sites in the Western academic world of all. A much wider range of constituencies from across the planet than usually considered in Transport Geography research should be involved as active participants in further discussions on what research is needed and how research praxis should be reconfigured. Methods from elsewhere in Geography and the wider social sciences to make those constituencies full and active participants in the genuine co-production of knowledge need to be adopted and adapted to the specific requirements of Transport Geography.

Moreover, it is important to mobilise some of the effects that new or renewed concepts with regard to the relationships between transport, climate change and space create. What Deleuze and Guattari understood as generating events disrupting habitual thinking and gesturing towards dynamisms, multiplicities and 
uncertainties that defy representation - is no objective in itself as far as research on those relationships is concerned, and transport geographers cannot remain content with concept creation. The goal is ultimately to complement the futures and trajectories of intervention into transport configurations that are opened up by prevailing (academic) knowledges about transport, climate change and space with further options to achieve low-carbon, robust and just transport configurations across the planet.

A key complement to the reinvention of concepts will be the development of new, and renewal of existing, coordinate systems and thus new ways of measuring quantitatively and otherwise - qualities and aspects of transport configurations. Of course, given that Deleuzian concepts (seek to) gesture at that which is beyond representation, any articulation in numbers, formulas and text of the new understandings about the relationships between transport, climate change and space that (re)new(ed) concepts enable is partial and limited. But some of the insights that follow the disruption of habitual thinking enabled by a Deleuzian (re)invention of concepts can be represented.

The specifics of how (re)new(ed) coordinate systems can or should be developed are beyond this paper, but briefly returning to Time Geography is instructive in this context. The invention of its core concepts, including the space-time prism, also triggered and entailed the invention of its well-known space-time diagrams and the space-time aquarium. Extensively criticised over the decades for its linear, objectivist and absolute take on time and space, this coordinate system did make it possible to represent changes to transport configurations and the elements that 
constitute them that could not be articulated by other representational systems. ${ }^{7}$ What makes the Time Geography example so interesting in the current context is that its reconfiguring of coordinate systems has exceeded Geography and influenced the disciplines of Urban Planning and Civil Engineering and transport planning processes in multiple cities and countries. Something similar can happen with reinvented concepts that relate to transport, climate change and space.

Notwithstanding its preliminary and partial character, the above discussion of adaptation might eventually help to reset the parameters of cross-disciplinary and non-academic discussions about the promotion of cycling or EVs. If so, then this might happen not only because it interconnects questions about greenhouse gas emission reduction with those about weather-related disruptions and the needs, capacities and preferences of potential users, including the poor, the oldest old, the illiterate, those on the wrong side of digital divides across spaces, in specific sites and places. It might also occur when and because transport geographers manage to develop new coordinate systems and approaches to track and measure - both quantitatively and qualitatively - the events generated by the adaptation concept and the questions this concept make possible. Specifying or even speculating about the precise nature of those coordinate systems and approaches is beyond this particular paper. Yet, given the rudimentary health and vigour of transport-related research in Geography, there is ample capacity and expertise in the Transport Geography community to realise the prospect of resetting the

\footnotetext{
${ }^{7}$ Examples are changes induced by changes to public transport routes and timetables or extended opening hours of services (e.g. Kwan et al., 2003; Neutens et al., 2010).
} 
parameters within which research and debates about climate change, transport and space has so far operated.

\section{References}

Barnett, C., Bridge, G., 2016. The situations of urban inquiry: thinking problematically about the city. International Journal of Urban and Regional Research 40(6), 1186-1204. Becker, A., Ng, A.K.Y., McEvoy, D., Mullett, J., 2018. Implications of climate change for shipping: ports and supply chains. Wiley Interdisciplinary Reviews: Climate Change $9(2)$, e508.

Bignall, S., Patton, P., 2010. Introduction - Deleuze and the postcolonial: conversations, negotiation, meditations. In: Bignall, S., Patton, P., eds., Deleuze and the Postcolonial, pp. 1-19. Edinburgh University Press, Edinburgh.

Bonham, J., 2006. Transport: disciplining the body that travels. The Sociological Review 54(1_Suppl), 57-74.

Boyce, D., Williams, H., 2015. Forecasting Urban Travel: Past, Present and Future. Edward Elgar, Cheltenham,

Brazil, W., White, A., Nogala, M., Caulfied, B., O’Connor, A., Morton, C., 2017. Weather and rail delays: analysis of metropolitan rail in Dublin. Journal of Transport Geography 59, 69-76.

Buchanan, T., 2017. Assemblage theory, or the future of an illusion. Deleuze Studies 11(3), 457-474.

Burns, L., Kaiser, B.M., Eds., 2012. Postcolonial Literature and Deleuze: Colonial Pasts, Differential Futures. Palgrave MacMillan, Basingstoke. 
Cameron, E.S., 2012. Securing Indigenous politics: a critique of the vulnerability and adaptation approach to the human dimensions of climate change in the Canadian Arctic. Global Environmental Change 22(1), 103-114.

Caset, F., Boussauw, K., Storme, T., 2018. Meet \& fly: sustainable transport academics and the elephant in the room. Journal of Transport Geography 70, 64-67.

Chapman, L., 2007. Transport and climate change: a review. Journal of Transport Geography 15(5), 354-367.

Chow, A.S.Y., 2016. Spatial-modal scenarios of greenhouse gas emissions from commuting in Hong Kong. Journal of Transport Geography 54, 205-213.

Conti, B., 2018. Modal shift and interurban mobility: environmentally positive, socially regressive. Journal of Transport Geography 69, 234-241.

Cook, P., 1998. Thinking the concept otherwise: Deleuze and expression. Symposium 2(1), 23-35.

Corcoran, J., Tao, S., 2017. Mapping spatial patterns of bus usage under varying local temperature conditions. Journal of Maps 13(1), 74-81.

Cresswell, T., 2006. On the Move: Mobility in the Modern Western World. Routledge, New York.

Dawson, D., Shaw, J., Gehrels, W.R., 2016. Sea-level rise impacts on transport infrastructure: the notorious case of the coastal railway line at Dawlish, England. Journal of Transport Geography 51, 97-109.

Deleuze, G., 1980. Spinoza, 09/12/1980, Power \& Classical Natural Right. Available at: http://possest.de/wp-content/uploads/2016/02/Gilles-Deleuze-Spinoza-Power-ClassicalNatural-Right-1-1.pdf (accessed 21 October 2018).

Deleuze, G., 1990. Logic of Sense. The Athlone Press, London.

Deleuze, G., 1998. Vincennes session of April 15, 1980, Leibniz seminar. Discourse 20(3), 77-97.

Deleuze, G., Guattari, F., 1994. What is Philosophy? Columbia University Press, New York. 
Dewey, J., 1922. Human Nature and Conduct: An Introduction to Social Psychology.

Henry Holt and Company, New York.

Dorries, H., Ruddick, S., 2018. Between concept and context: reading Gilles Deleuze and Leanne Simpson in their in/commensurabilities. cultural geographies 25(4), 619-635. Ferranti, E., Chapman, L., Lee, L. Jaroszweski, D., Lowe, C., McCulloch, S., Quinn, A., 2017. The hottest July day on the railway network: insights and thoughts for the future. Meteorological Applications 25(2), 195-208.

Fraser, N., 2008. Scales of Justice: Reimagining Political Space in a Globalizing World. Polity, Cambridge.

Geels, F.W., 2012. A socio-technical analysis of low-carbon transitions: introducing the multi-level perspective into transport studies. Journal of Transport Geography 24, 471482.

Ghosh, B., Schot, J., 2019. Towards a novel regime change framework: studying mobility transitions in public transport regimes in an Indian megacity. Energy Research \& Social Science 51, 82-95.

Givoni, M., 2006. Development and impact of the modern high-speed train: a review. Transport Reviews 26(5), 593-611.

Givoni, M., Banister, D., Eds., 2013. Moving Towards Low Carbon Mobility. Edward Elgar, Cheltenham.

Hägerstrand, T., 1970. What about people in regional science? Papers in Regional Science 24(1), 7-24.

Henderson, J., 2006. Secessionist automobility: racism, anti-urbanism, and the politics of automobility in Atlanta, Georgia. International Journal of Urban and Regional Research 30(2), 293-307.

Hoogma, R., Kemp, R., Schot, J., Truffer, B., 2002. Experimenting for Sustainable Transport: The Approach of Strategic Niche Management. Spon Press, London. Huang, L., Lasserre, F., Alexeeva, A., 2015. Is China's interest for the Arctic driven by Arctic shipping potential? Asian Geographer 32(1), 59-71. 
Hupkes, G., 1982. The law of constant travel time and trip-rates. Futures 14(1), 38-46. IPCC (Intergovernmental Panel on Climate Change), 1996. Climate Change 1995. Impacts, Adaptations and Mitigation of Climate Change: Scientific-Technical Analyses. Cambridge University Press, Cambridge.

IPCC (Intergovernmental Panel on Climate Change), 2001. Climate Change 2001: Impacts, Adaptation, and Vulnerability. Cambridge University Press, Cambridge. IPCC (Intergovernmental Panel on Climate Change), 2014. Climate Change 2014. Impacts, Adaptation, and Vulnerability Part A: Global and Sectoral Aspects. Cambridge University Press, Cambridge.

IPCC (Intergovernmental Panel on Climate Change), 2018. Global Warming of $1.5^{\circ} \mathrm{C}$. Available at: http://www.ipcc.ch/report/sr15/ (last accessed 19 October 2018). Ishaya, S., Abaje, I.B., 2008. Indigenous people's perception on climate change and adaptation strategies in Jema'a local government area of Kaduna State, Nigeria. Journal of Geography and Regional Planning 1(8), 138-143.

Kaufmann, V., 2002. Re-thinking Mobility. Ashgate, Farnham.

Keskisaaria, V., Ottelin, J., Heinonen, J., 2017. Greenhouse gas impacts of different modality style classes using latent class travel behavior model. Journal of Transport Geography 65, 155-164.

Kwan, M.-P., Murray, A.T., O’Kelly, M.O., Tiefelsdorf, M., 2003. Recent advances in accessibility research: representation, methodology and applications. Journal of Geographical Systems 5(1), 129-138.

Lasserre, F., Beveridge, L., Fournier, M., Têtu, P.-L., Huang, L., 2016. Polar seaways? Maritime transport in the Arctic: an analysis of shipowners' intentions II. Journal of Transport Geography 57, 105-114.

Latour, B. 1993. We Have Never Been Modern. Harvard University Press, Cambridge, MA.

Latour, B., 2018. Down to Earth: Politics in the New Climatic Regime. Polity, Cambridge. 
Litman, T., 2006. Lessons from Katrina and Rita: what major disasters can teach transportation planners. Journal of Transportation Engineering 132(1), 11-18.

Loo, B.P.Y., 2018. Unsustainable Transport and Transition in China. Routledge, Abingdon.

Lucas, K., 2012. Transport and social exclusion: where are we now? Transport Policy 20, 105-113.

Lucas, K., Pangbourne, K., 2012. Transport and climate change policy in the United Kingdom: a social justice perspective. In: Ryley, T., Chapman, L., Eds., Transport and Climate Change, Emerald, Bingley, pp. 287-312.

Luo, X., Dong, L., Dou, Y., Liang, H., Reng, J., Fang, K., 2017. Regional disparity analysis of Chinese freight transport CO2 emissions from 1990 to 2007: Driving forces and policy challenges. Journal of Transport Geography 56, 1-14.

Markham, F., Young, M., Reis, A., Higham, J., 2018. Does carbon pricing reduce air travel? Evidence from the Australian 'Clean Energy Future' policy, July 2012 to June 2014. Journal of Transport Geography 70, 206-214.

Marsden, G., Reardon, L., Eds., 2018. Governance of the Smart Mobility Transition. Emerald, Bingley.

May, T., 2005. Gilles Deleuze: An Introduction. Cambridge University Press, Cambridge. McCann, E., Roy, A., Ward, K., 2013. Assembling/worlding cities. Urban Geography 34(5), 581-589.

McCreary, T.A, Milligan, R.A., 2014. Pipelines, permits, and protests: Carrier Sekani encounters with the Enbridge Northern Gateway Project. cultural geographies 21(1), 115-129.

Medien, K., 2019.3 Deleuze in Palestine. Theory, Culture \& Society, in press. DOI: 10.1177/0263276418816369.

Mignolo, W., 2011. The Darker Side of Western Modernity: Global Futures, Decolonial Options. Duke University Press, Durham, NC. 
Mokhtarian, P., Chen, C., 2004. TTB or not TTB, that is the question: a review and analysis of the empirical literature on travel time (and money) budgets. Transportation Research Part A: Policy and Practice 38(9-10), 643-675.

Morton, T., 2015. Hyperobjects: Philosophy and Ecology after the End of the World. University of Minneapolis Press, Minneapolis, MN.

Mouffe, C., 2005. On the Political. Routledge, London.

Na, J.-H., Choi, A.-Y., Ji, J., Zhang, D., 2017. Environmental efficiency analysis of Chinese container ports with $\mathrm{CO} 2$ emissions: an inseparable input-output SBM model. Journal of Transport Geography 65, 13-24.

Neutens, T., Schwanen, T., Witlox, F., De Maeyer, P., 2010. Equity of urban service delivery: a comparison of different accessibility measures. Environment and Planning A 42(7), 1613-1635.

Ng, A.K.Y., Andrews, J., Babb, D., Lin, Y., Becker, A., 2018. Implications of climate change for shipping: opening the Arctic seas. Wiley Interdisciplinary Reviews: Climate Change 9(2), e516.

Ng, A.K.Y., Chen, S.-L., Cahoon, S., Brooks, B., Yang, Z., 2013. Climate change and the adaptation strategies of ports: the Australian experiences. Research in Transportation Business \& Management 8, 186-194.

Noland, R.B., Lem, L.L., 2002. A review of the evidence for induced travel and changes in transportation and environmental policy in the US and the UK. Transportation Research Part D: Transport and Environment 7(1), 1-26.

Olsen, J., Nenadheva, M., 2018. Adaptive capacity in the context of increasing shipping activities: a case from Solovetsky, Northern Russia. Polar Geography, in press. DOI: 10.1080/1088937X.2018.1513960.

Owusu, M., Nursey-Bray, M., Rudd, D., 2019. Gendered perception and vulnerability to climate change in urban slum communities in Accra, Ghana. Regional Environmental Change 19(1), 13-25. 
Plyushteva, A., Schwanen, T., 2018. Care-related journeys over the life course: thinking mobility biographies with gender, care and the household. Geoforum 97, 131-141.

Quijano, A., 2000. Coloniality of power and eurocentrism in Latin America. International Sociology 15(2), 215-233.

Quinn, A.D., Ferranti, E.J.S., Hodgkinson, S.P., Jack, A.C.R., Beckford, J., Dora, J.M., 2018. Adaptation becoming business as usual: a framework for climate-change-ready transport infrastructure. Infrastructures 3(2), 10.

Rabinow, P., 1997. Polemics, politics, and problematizations: an interview with Michel Foucault. In: Rabinow, P., Ed., Michel Foucault - Ethics: Essential Works of Foucault 1954-1984, Volume 1, pp. 111-119. Penguin, London.

Preston, J., Rajé, F., 2007. Accessibility, mobility and transport-related social exclusion. Journal of Transport Geography 15(3), 151-160.

Rip, A., Kemp, R., 1998. Technological change. In: Rayner, S., Malone, E.L., Eds., Human Choice and Climate Change, Volume 2, pp. 327-399. Battelle Press, Columbus, $\mathrm{OH}$.

Rittel, H.W.J., Webber, M.M., 1973. Dilemmas in a general theory of planning. Policy Sciences 4(2), 155-169.

Sanchez, T., Brenman, M., 2008. Transportation equity and environmental justice: lessons from Hurricane Katrina. Environmental Justice 1(3), 73-79.

Schwanen, T., 2015a. The bumpy road toward low-energy mobility: case studies from two UK cities. Sustainability 7(6), 7086-7111.

Schwanen, T., 2015b. Understanding process: can transport research come to terms with temporality? In: Hickman, D., Bonilla, D., Givoni, M., Banister, D., Eds., International Handbook on Transport and Development, pp. 660-674. Edward Elgar, Cheltenham. Schwanen, T., 2015c. Beyond instrument: smartphone app and sustainable mobility. EJTIR 15(4), 675-690.

Schwanen, T., 2016a. Geographies of transport I: reinventing a field? Progress in Human Geography 40(1), 126-137. 
Schwanen, T., 2016b. Rethinking resilience as capacity to endure: automobility and the city. City 20(1), 152-160.

Schwanen, T., 2018. Towards decolonised knowledge about transport. Palgrave Communications 4, 79.

Schwanen, T., Banister, D., Anable, J., 2011. Scientific research about climate change mitigation in transport: a critical review. Transportation Research Part A: Policy and Practice 45(10), 993-1006.

Sheller, M., 2015. Racialized mobility transitions in Philadelphia: connecting urban sustainability and transport justice. City \& Society 27(1), 70-91.

Sheller, M., Urry, J., 2000. The city and the car. International Journal of Urban and Regional Research 24(4), 737-757.

Smith, D.W., 2012. On the nature of concepts. Parallax 18(1), 62-73.

Spivak, G.C., 1988. Can the subaltern speak? In: Nelson, C., Grossverg, L., eds., Marxism and the Interpretation of Culture, pp. 271-313. Macmillan Education, Basingstoke.

Stapleton, L., Sorrell, S., Schwanen, T., 2016. Estimating direct rebound effects for personal automotive travel in Great Britain. Energy Economics 54, 313-325.

Spotswood, F., Chatterton, T., Tapp, A., Williams, D. 2015. Analysing cycling as a social practice: An empirical grounding for behaviour change. Transportation Research Part F: Traffic and Psychology 29, 22-33.

Sorrell, S., Stapleton, L., 2018. Rebound effects in UK road freight transport.

Transportation Research Part D: Transport and Environment 63, 156-174.

Steer Davies Gleave, 2017. Carplus Annual Survey of Car Clubs: 2016/17, London. Steer Davies Gleave, Leeds.

Stengers, I., 2011. Comparison as a matter of concern. Common Knowledge 17(1), 48-63.

Stengers, I., 2015. In Catastrophic Times. Open Humanities Press and meson press, Lüneburg. 
Swyngedouw, E., 2009. Apocalypse forever? Post-political populism and the spectre of climate change. Theory, Culture \& Society 27(2-3), 213-232.

Thill, J.-C., Kim, M., 2005. Trip making, induced travel demand, and accessibility. Journal of Geographical Systems 5(2), 229-248.

Upham, P., Virkamäkia, V., Kivimaa, P., Hildén, M., Wadud, Z., 2015. Socio-technical transition governance and public opinion: The case of passenger transport in Finland. Journal of Transport Geography 46, 210-219.

Weiner, E., 2016. Urban Transportation Planning in the United States: History, Policy, and Practice, Fifth Edition. Springer, Basel.

Wynter, S., McKittrick, K., 2015. Unparalleled catastrophe for our species? Or to give humanness a different future: conversations. In: McKittrick, K., Ed., Sylvia Wynter: On Being Human as Praxis, pp. 9-89. Duke University Press, Durham, NC.

Zahavi, Y., Talvittie, A., 1980. Regularities in travel time and money expenditures.

Transportation Research Record 780, 13-19.

Zhao, P., Kwan, M.-P., Qin, K., 2017. Uncovering the spatiotemporal patterns of CO2 emissions by taxis based on individuals' daily travel. Journal of Transport Geography 62, $122-135$. 